\title{
LETTERS
}

\section{Symptom of cultural narcissism}

Thank you for this reminder ${ }^{1}$ that health is so much more than health care, and is inevitably bound up in relationships. Perhaps the current unmet needs among Canada's Indigenous people are a symptom of a particular kind of cultural narcissism, one that deems the well-being of certain kinds of people to be more important than that of others - based on cultural identity. I hope we can build bridges, both interpersonal and structural, that will embody mutual respect and innovative approaches, between colonial and Indigenous societies.

\section{Randall W. Friesen MD}

General surgeon and area chief of staff, Northeast, Saskatchewan Health Authority; Department of Surgery, University of Saskatchewan, Saskatoon, Sask.

- Cite as: CMAJ 2018 October 22;190:

E1262. doi: 10.1503/cmaj.70337

\section{Reference}

1. McKennitt DW. Inequity a root cause of poor health among Indigenous peoples [letter]. CMAJ 2018; 190:E807.

Competing interests: None declared. 